\title{
Wonder and Following-Analysis on Reasons for Female's following to Advertisements
}

\author{
Min Li \\ Shandong Normal University, Ji'nan, 250014, China
}

Keywords: Advertisement concept. Visual Wonder. Symbolization. Identification. Female's following

\begin{abstract}
Based on the fact that the females follow the advertisement, three main reasons for female's following are analyzed: first, the transmission concept of advertisements and the female's aesthetic faith; second, symbolization and identification; third, advertisement wonder and female's watching. The analysis is aimed to reveal the essence of advertisement wonder and the deep social reasons for the female's following. From this aspect, the lack of public space in China and the necessity for construction of public construction of artistic criticism are verified.
\end{abstract}

\section{Introduction}

In the visual times dominated by image and video, the "vision" of advertisement is more and more concerned and highlighted. The purpose of emphasizing vision in advertisements is to "refer", but not "able to refer". The image value or symbolic value of commodities is far greater than their use value, and it has become the striving direction to symbolize the image value of commodities, so as to be accepted by the consumers.

The unremitting temptation of advertisements and the female's easy following have become the outstanding phenomena in the contemporary visual culture. According to the analysis based on examples, the success of temptation and reasons for the following are mainly reflected in the following:

\section{Transmission concept of advertisement and aesthetic faith of female}

As a form of visual transmission, advertisement is aimed to transmit information through symbols. Its audiences are mainly female, or the information of advertisement transmission including female is some specific concepts, i.e. advertisement is to shape a qualified and even perfect female by the society and oneself simultaneously, while the aesthetic concept undertaken by the females for a long time will make them deeply identify with the advertisement transmission concept and are willing to follow it.

\section{Advertisement transmission concept}

Females have become the deserved main forces in the contemporary consumption century to the extent that "her century" has become the pronoun for market demand in the $21^{\text {st }}$ century, and the female consumers often maintain a higher loyalty and great recommendation to the brands. Therefore, for the advertisements, it is of vital importance to win the female audiences.

In terms of publicity concept, advertisements always emphasize the females' weakness and disadvantages, point the reasons making female fall in dilemma and suffer the unequal treatment and propose a so-called solution that make people satisfied, for example, the cosmetics, clothes and slimming advertisements aimed at the female. All these warm the females of problems met, their situation, personality lacking and the severity of insufficient charm and advise females that if they do not change themselves, all will become worse. While the effective approach to change this situation is to accept and consume the services or commodities provided by the advertisements.

The change of survival context and various difficulties faced make female place high hopes on the products. As the base, the practicability supports the image function and symbolic function. For example, cosmetics do not only make a women become more beautiful, but more importantly, it will 
make her obtain love, self-confidence and more opportunities. In order to adapt to the individual demands brought by the modernization, the transmission concept of advertisements is also changed on the original basis, for example, through consumption, females can become more individualized and independent. But there are two points worth concerning, first, in terms of the representation form of advertisements, obviously, the spokesmen of these images adopt the figures of speech of "cover girl", and their qualification is a model created; for example, in terms of the publicity concept, the females full of individuality, self-confidence and independence created in the advertisements are independent from men, and even ignore men, presenting a suspended strong stance of above a certain reasonable relation. In nature, this attitude distorts the source for weak position of female. Through these measures, advertisements seem to provide a reasonable reference system and standard (they represent truth and reality), and express such violent model and distorted concept in a low-pitched and kind speech, making females willing to follow blindly.

\section{Aesthetic faith of female}

Facts have proved that the females' self cognition and adherence to the aesthetic faith also endure the effect of the concept publicized by the advertisements. Females, regulated by the society, short of self-awareness and lack of solid and sound faith support often depend on the regulations of the external factors in the concept and faith of beauty, fashion, health and taste. It is very difficult for them to define themselves and the meaning of beauty and fashion by starting from themselves. Because the adherence character of aesthetic faith make women easy to be lost in the repeated temptation and skillful and patient persuading of advertisements, so as to recognize the fashion and cater to others.

Females are thirst to be concerned, perform themselves, become the focus and obtain some comfort, recognition or love by pursuing the fashion, and such irrational consumption gradual make them become the "golden consumption groups". It can be seen that when seeing advertisements, females often see their thirst and hope, and obtain the pleasant sensation of releasing and realizing desire. $^{[1]}$

\section{Symbolization and identification}

Advertisements use images, vides, texts and other symbols to transmit information, and the symbols in the advertisements have special directions and significances.

\section{Significances of advertisement symbol}

The symbols in advertisements have the characteristics of to be able to refer and being referred to. Through repeated application, advertisement symbolize, mold and even ritualize many forms and means, gradually changing the arbitral relation between being able to refer and being referred to, and creating a conventionalized symbolic form and transmission strategy with stable relation.

"We do not only purchase the things we need, but it is the purchasing symbols that tell us what to buy. " ${ }^{[2]}$ Advertisements cultivate a group of pseudo-individualized consumption idols, who provide life samples for their sisters with their "personal practice". Therefore, advertisement both use the instinct demands of female consumes, and meanwhile make efforts to develop their potential desire, making them place high hopes on the symbolic value of advertisements. ${ }^{[3]}$ Under the instigation of fetishism, no matter how attractive the symbolic value of symbols is, it is unable to cover the standardization, homogeneity and control behind the symbols.

\section{Female identification and verification}

Like females and commodities, advertisements themselves are also commodities, capitals and values. As a heterogeneous product, advertisements make joint efforts to construct the social context in which they survive and jointly follow the survival logistic. Actually, in contemporary times dominated by the consumption culture, mass culture and visual culture, the females and males who are deeply socialized have their self-awareness in the lost state, and their self-verification is from the society. Despite of dissatisfaction and resistance, females are thirst to enter the system with set rules to endow themselves with the possibility of existence. 
In advertisements, based on the aspect of "others", females are concerned by the camera as things; according to the standard image (impressive stature, moving expression, voluptuous gesture and recommending products by setting an example), "others" shoot and divide the females' body; the partial aesthetic and standard of the of the body can be realized by consumption. They are "annihilated symbolically", and the specific female image becomes a conventionalized image in the advertisements. While the attempt and practice of using these symbols to please the audiences no doubt extend and even enhance the fact that the female's self-awareness is banned.

Baudrillard, French sociologist once pointed out that due to the imaging and symbolization of consumption, the modern consumption transmission is more and more representing the characteristics of "differentiation", i.e. to pursue individualization and uniqueness, and the characteristic of the so-called "style transmission" is also more and more outstanding ${ }^{[4]}$. While the acceptance of female to advertisement also belongs to "style consumption", which is both the process of females to obtain individualized experience, personal style and self-significance and also the means to establish and convey the group styles and characteristics. Having the group characteristics is the premise to obtain the guarantee of spiritual safety and highlight the individualized characteristics. The only way to "avoid the disordered world of nightmare" is to "remain in the regulations established" and remain in the significance most widely accepted. Any violation of this law of existence will cause one to "generate an unbearable mental stress" and fall in the ambiguity of non-reality. ${ }^{[5]}$ Besides, according to the explanation of Marx Web, "class situation" is completely "market situation". The females of the same class situation and group have the similar consumption ability and consumption tastes. In the book Individual Characteristics, French sociologist Pierre Bourdieu pointed out that the modern consumption is a method to establish the difference between social groups. I consume therefore I am and I'm classified. Being classified means to be classified into a certain field or certain cultural taste to obtain the social sense of belonging. While the cultural taste depends on the operation of power system, and isolation of cultural taste (elegant/common, profound/superficial, noble/humble), actually reflecting a power relation, closely related with the economic capital, social capital and cultural capital.

\section{Advertisement wonder and females' watching}

Nobel economic prize winner Herbert Simon once pointed out that with the development of information, what will become valuable is not information but attention. And advertisement are familiar with the game rules in the economic times of attention.

\section{Sub-consciousness and visual trespass}

Why advertisements are "paid attention to" because of their persistent playing and expression. There is the concept of "perceptive threshold" in psychology, some signal can be perceived only when its strength surpasses the perceptive threshold, that is to say, the stimulation acting on various receptors can be perceived only when reaching a certain strength. But there are also many signals with strengthen higher than the "login threshold" of humans (influence on eyes, ears and other organs) while lower than the perceptive threshold. People might ignore them, but these signals will influence the human behaviors silently, i.e. the "sub-consciousness" in psychology. While advertisements use this soul controlling method of strategic consciousness and sub-consciousness. Although the western countries expressly ban the advertising with sub-consciousness, by virtue of the hidden and persistent strategy, advertisements constitute the collective perception and forceful watching of the society, while this stimulation to the people's survival space and life time is invasive and corrosive, making people have no where to escape.

\section{Visual wonder of advertisements}

Advertisements fully master the visual hobby of the contemporary people, the creation of various visual wonders with modern high technologies brings unprecedented visual pleasant situation: intuitive, satisfying, current and future hope. In terms of the expression method, advertisements use various wonders: body wonder, beauty wonder, action wonder and scene wonder to attract the eyeball of females. 
Due to the artificialization, stylization, virtualization, stylization and categorization of advertisement symbols, it is undeniable that the phenomenon of "nerve contentment" in psychology is brought. Therefore, advertisements attempt to bring something new while getting rid of the old, continuously invent and create new visual wonders and realize the colonization to the human space and time. Complying with the logistics of times, the advertisements present unprecedented and dizzy landscapes with continuous increasing images. As said by Guy Debord bitterly, "in the society with spreading modern production conditions, the whole life presents a huge agglomeration of wonders. Once all things that survived directly now become symbol purely" [6] The so-called purely symbolic meaning means that many wonders appearing in the advertisements such as appearance, body, plot, scene and other prototypes are not from the reality, but from the achievements of modern high-end technology, being the imaging, simulacrum and appearance said by Guy Debord, a surreal existences. In nature, these images of simulacrums eliminate the specific indication to become a symbol of self-simulation and referring. They are plain, not deep and temporary, and they are in the "story", but not survive in the whole logistic space which is unable to be seen clearly full of "things" difficult to be mastered and "situation".

\section{"Watching" of females}

Except the complexity of "watching" and "being watched" socially, people's watching to the idealized image in advertisements can be a relatively fee appreciation physiologically and visually, and people may not concern the self "watching" and "being watched". While beyond the advertisements, the watching to the same sex or different sex is a kind of watching with psychology, vision and behaviors more understood. The visual consumption to advertisement wonder is both realistic (experience, typical) and unrealistic (psycholagny and ideal).

The research of psychology has demonstrated that the advertisement films with female, especially beautiful women as the role are more influential on female than on male. Females' mode of perception, review attitude and psychological cognition to the visual wonders is different from those of male. For example, for the concern to a fashionable beauty, males often take the sexual physiology and sexual psychology as the potential motive power, which is mainly from the desire psychology of aesthetics or sexual passion. While the females' concern to the beauty often includes the desire of being envying, jealous and even simulation. French sociologist Tarde who researched "simulation" first pointed out that as the social existence, social person is the simulator in nature, and people surpass their plain individuality through simulation.

Therefore, according to the theory of Lacan, women's watching advertisements is not only the watching of women (subject) to advertisements (others), but also the seductive attention of advertisements as the desire target to women, being a mutual staring and interaction between the subject and others and the dominated position of the traditional watching is canceled. The female consumers' concern, interest, acceptance and further consumption to the "examples" and goods in the advertisements are actually the process of materializing themselves step by step, while advertisements decides the completion and realization of self-significance between watching and being watched.

The motivation of females to follow advertisement is not from the self-awareness of self-realization and the judgment awareness of value rationality, such consumed behaviors controlled by the tool rationality will make females lose their judgment ability to aesthetics more and more. The human consumption demand is based on the more human context and the freedom of females' self-experience, and the society needs more significant consumption behaviors and need to break through many set rules, regulations and restrictions, eliminate the barrier and realize the disenchantment of advertisement and humanity.

\section{Acknowledgments}

This paper is one of the achievements of human and social science research objects in higher institutes in 2012. Project name: Symbol and Exchange, project number: J12WK60 


\section{References}

[1] Zhou Xiaohong, Fashion and Social Change, published in Cultural Change at the Turn of the Century [M] edited by Zhou Xian, Shanghai, Shanghai Far East Publishers, 1998, 291-292.

[2] George Ritzer, Postmodern Social Theory, [M] translated by Xie Lizhong et al., Beijing: Huaxia Publishing House, 2003. 111

[3] [French] Jean Baudrillard, Consumption Society [M], translated by Liu Chengfu, Jin Zhigang, Nanjing, Nanjing University Press, 2000. 138

[4] Guo Qingguang, Communication Tutorial [M]. Beijing: China Renmin University Press, 1999. 55

[5] Berger, Religion in Modern Consciousness [M] Refer to Croods Kaufman Women’s Body, Men’s View [M] translated by Xie Qing and Mayue, Beijing: Social Sciences Academic Press, 2001. 282 